\title{
Traumatic Cervical Pneumorrhachis
}

\section{Zolnourian $\mathbf{A}^{1 *}$, McColgan $\mathbf{P}^{3}$, Sherlala $\mathbf{K}^{2}$ and Kuruvath $\mathbf{S}^{2}$}

${ }^{1}$ Departments of Neurological Surgery, University Hospital of Coventry and Warwickshire, Clifford Bridge Road, Coventry, CV2 2DX, UK

${ }^{2}$ Departments of Neuroradiology, University Hospital of Coventry and Warwickshire, Clifford Bridge Road, Coventry, CV2 2DX, UK

${ }^{3}$ UCL Institute of Neurology and National Hospital for Neurology and Neurosurgery, Queen Square, WC1N 3BG, UK

\begin{abstract}
Pneumorrhachis (Intraspinal air or intraspinal pneumocele) is a rare association with closed head injury. latrogenic causes are well known and are often secondary to diagnostic procedures. However, there are only a few case reports in the literature following trauma. We present a case of traumatic pneumorrhachis following a head injury with base of skull fracture. This was treated conservatively and patient made a full recovery.
\end{abstract}

Keywords: Pneumorrhachis; Intraspinal pneumocele; Intraspinal air; Base of skull fracture

\section{Introduction}

Pneumorrhachis refers to air within the spinal canal. Traumatic pneumorrhachis is a very rare entity of which there are only a few reported cases. We present a young male who sustained cervical pneumorrhachis following a road traffic accident.

\section{Case Reports}

A 25 year old man was brought to the emergency department after being struck by a car, having sustained head injuries. On arrival, his vitals were stable, pupils equal and reactive and moving all his limbs appropriately. His Glasgow Coma Scale (GCS) on arrival was E4 V2 M6. Blood was noted in the right external auditory meatus. He became agitated and restless needing intubation and ventilation. Trauma series Computer Tomography (CT) scans of the brain (Figure $1 \mathrm{~A}$ and $1 \mathrm{~B}$ ) and spine (Figure $2 \mathrm{~A}$ and $2 \mathrm{~B}$ ) revealed bilateral cerebral contusions, right temporal bone fracture with petechial haemorrhage, pneumocephalus and air in the spinal canal at C1-4 vertebrae levels. He was initially managed medically, but due to raised intracranial pressure he underwent bifrontal decompressive craniectomy. The pneumorrhachis was treated conservatively and patient made an uneventful recovery.

\section{Discussions}

Pneumorrhachis is a rare condition. Pathophysiologically, it is divided into three main categories; nontraumatic, traumatic and iatrogenic. Furthermore, anatomical classification of pneumorrhachis is based on the position of spinal air in relation to the dura mater, namely intradural (air within the subdural or subarachnoid space) and extradural (epidural air) [1].

Traumatic pneumorrhachis in association with closed head injury is a very rare condition and there are only a few reported cases resulting from base of skull fracture in the literature [2-7]. It has been seen following blunt chest trauma, traumatic pneumothorax, multiple thoracic fractures, cervical spine injuries and pelvic injuries. It is thought to be a marker of the severity of trauma. Iatrogenic causes are well known i.e. following surgical and diagnostic interventions, malignancy and its associated therapy [1].

Presence of pneumorrhachis indicates that there is almost certainly an associated air distribution elsewhere in the body. In patients where there is a background history of trauma physician must have a high index of suspicion to search for accompanying intracranial injuries. X-rays are useful diagnostic tools; however, the gold standard diagnostic modality remains CT [1].

We believe the pathogenesis of pneumorrhachis in our patient is the result of right temporal bone skull base fracture which caused a tear in the dura mater overlying the bone. This in turn provided a direct communication between the pneumatised mastoid bone and the intracranial space. Air then travelled through the punctured dura mater into the prepontine cistern. The increased intracranial pressure, resulting from the cerebral contusions and oedema, forced the penetrated air to travel caudally in to the cervical subarachnoid space.

Traumatic cervical and intradural pneumorrhachis are often found in combination with anterior cranial fossa injuries. On the other hand skull base or middle and posterior cranial fossae fractures are mostly seen with intracranial subarachnoid air and pneumocephalus [1]. Subarachnoid pneumorrhachis can also be the result of an isolated penetrating spinal injury without an underlying head injury and it is almost always associated with pneumocephalus [8].

Moreover, pnemorrhachis has been described to be complicated by tension pneumocephalus [9]. Meningitis is also a potential complication of subarachnoid pneumorrhachis, as a torn dura may serve as a potential portal of entry for bacteria [10]. Therefore repairing the torn dura should always be considered, as it is associated with $25 \%$ risk of meningitis or may cause persistent pneumocephalus $[11,12]$.

Most patients with pneumorrhachis are asymptomatic. Air itself does not usually cause any harm, and is often absorbed spontaneously with the air being passed directly into the blood stream in several days. Symptoms of discomfort, pain and even neurological deficits have been reported due to pneumorrhachis following lumbar and epidural anaesthesia, some of which have required surgical decompression [13].

However, there has been one reported case of traumatic pneumorrhachis with associated pneumocephalus causing sensory symptoms, which was treated conservatively with oxygen

*Corresponding author: Ardalan Zolnourian, Departments of Neurological Surgery, University Hospital of Coventry and Warwickshire, Clifford Bridge Road, Coventry, CV2 2DX, UK, E-mail: z.ardalan@googlemail.com

Received May 18, 2013; Accepted July 29, 2013; Published July 31, 2013

Citation: Zolnourian A, McColgan P, Sherlala K, Kuruvath S (2013) Traumatic Cervical Pneumorrhachis. J Trauma Treat 2: 173. doi:10.4172/2167-1222.1000173

Copyright: (c) 2013 Zolnourian A, et al. This is an open-access article distributed under the terms of the Creative Commons Attribution License, which permits unrestricted use, distribution, and reproduction in any medium, provided the original author and source are credited. 

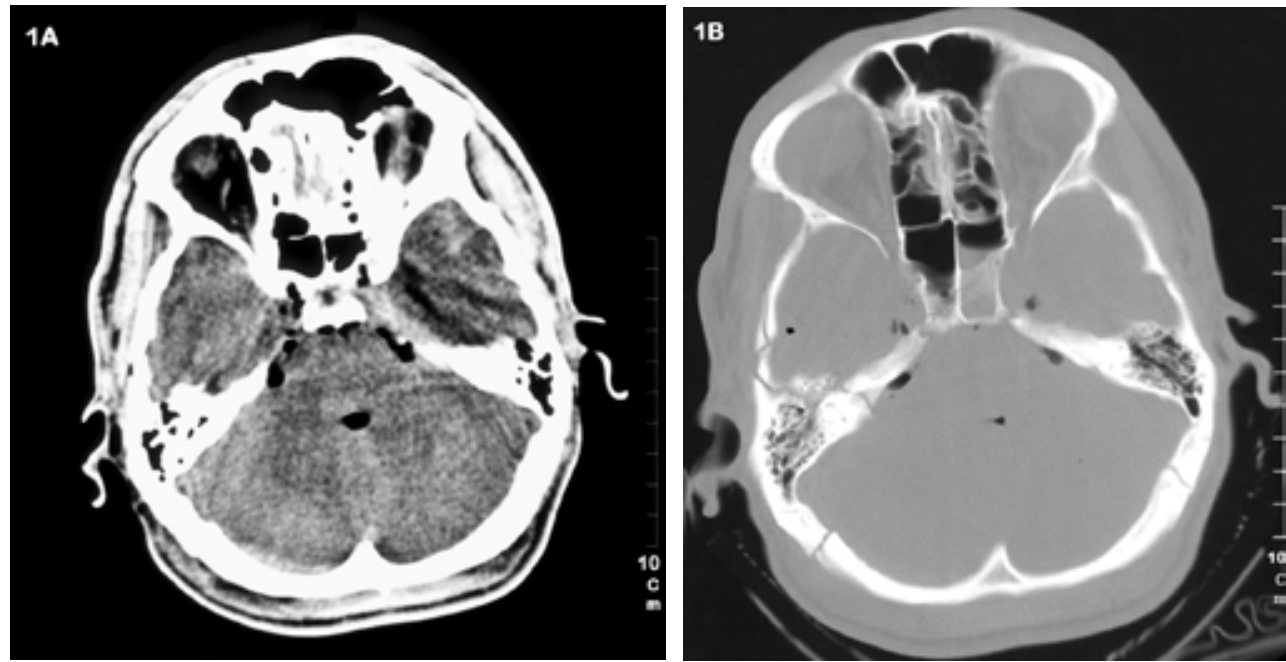

Figure 1 A and B: Axial plain and bone-window CT brain showing free gas in the subarachnoid space, prepontine and cerebellopontine region and the fourth ventricle.
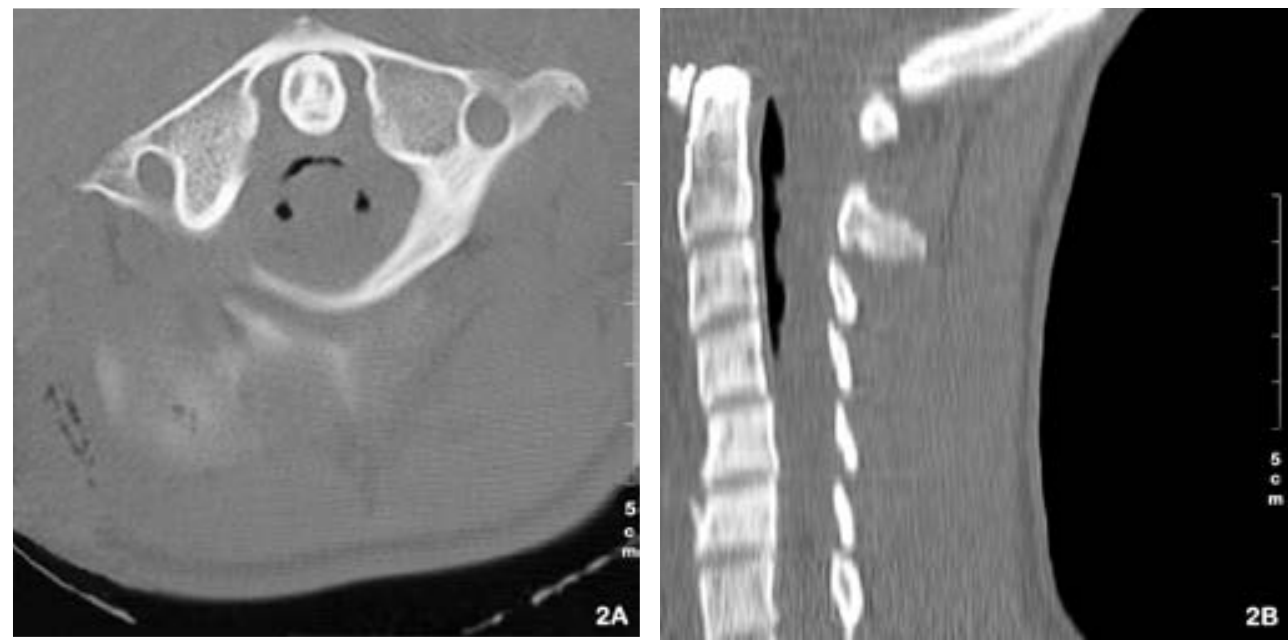

Figure 2 A and B: Axial CT cervical spine showing free gas at C1 level. Extension of free gas from C1 to C4 level in the subarachnoid space is evident on the sagittal view.

supplementation [6]. Caution should be taken to avoid using anaesthetic gases i.e. nitric oxide as it could expand the extent of intraspinal air and potentially cause symptoms [8]. Nevertheless, management is tailored to the individual patient's clinical assessments.

\section{Conclusions}

Intraspinal air is often an iatrogenic phenomenon. Traumatic pneumorrhachis associated with head injury is extremely rare. It is thought to be a marker of the severity of trauma. Pneumorrhachis is often a self-limiting condition. Management should be individualised but remains mostly conservative. In the presence of pneumorrhachis trauma specialist should always search for accompanying injuries and beware of potential complications such as meningitis and tension pneumocephalus.

\section{References}

1. Oertel MF, Korinth MC, Reinges MH, Krings T, Terbeck S, et al. (2006) Pathogenesis, diagnosis and management of pneumorrhachis. Eur Spine J 15 Suppl 5: 636-643.
2. Newbold RG, Wiener MD, Vogler JB 3rd, Martinez S (1987) Traumatic pneumorrhachis. AJR Am J Roentgenol 148: 615-616.

3. Sinha PA, Mantle M (2000) Cervical pneumorrhachis. Clin Radiol 55: 569-570.

4. Inamasu J, Nakamura Y, Saito R, Kuroshima Y, Ichikizaki K (2002) Air in the spinal canal after skull base fracture. Am J Emerg Med 20: 64-65.

5. Cayli SR, Koçak A, Kutlu R, Tekiner A (2003) Spinal pneumorrhachis. Br J Neurosurg 17: 72-74.

6. Yousaf I, Flynn P, McConnell R (2003) Symptomatic intraspinal pneumocoele resulting from closed head injury. Br J Neurosurg 17: 248-249.

7. Akay S, Bayram B (2008) Traumatic pneumorrhachis: a rare entity of trauma Int $\mathrm{J}$ Emerg Med 1: 53.

8. Day CJ, Nolan JP, Tarver D (1994) Traumatic pneumomyelogram. Implications for the anaesthetist. Anaesthesia 49: 1061-1063.

9. Bilsky MH, Downey RJ, Kaplitt MG, Elowitz EH, Rusch VW (2001) Tension pneumocephalus resulting from iatrogenic subarachnoid-pleural fistulae: report of three cases. Ann Thorac Surg 71: 455-457.

10. Frantz PT, Battaglini JW (1980) Subarachnoid-pleural fistula: unusual complication of thoracotomy. J Thorac Cardiovasc Surg 79: 873-875. 
Citation: Zolnourian A, McColgan P, Sherlala K, Kuruvath S (2013) Traumatic Cervical Pneumorrhachis. J Trauma Treat 2: 173. doi:10.4172/21671222.1000173

Page 3 of 3

11. North JB (1971) On the importance of intracranial air. Br J Surg 58: 826-829.

12. Goh BK, Yeo AW (2005) Traumatic pneumorrhachis. J Trauma 58: 875-879.
13. Kennedy TM, Ullman DA, Harte FA, Saberski LR, Greenhouse BB (1988) Lumbar root compression secondary to epidural air. Anesth Analg 67: 11841186 